\title{
The popular culture of medicine
}

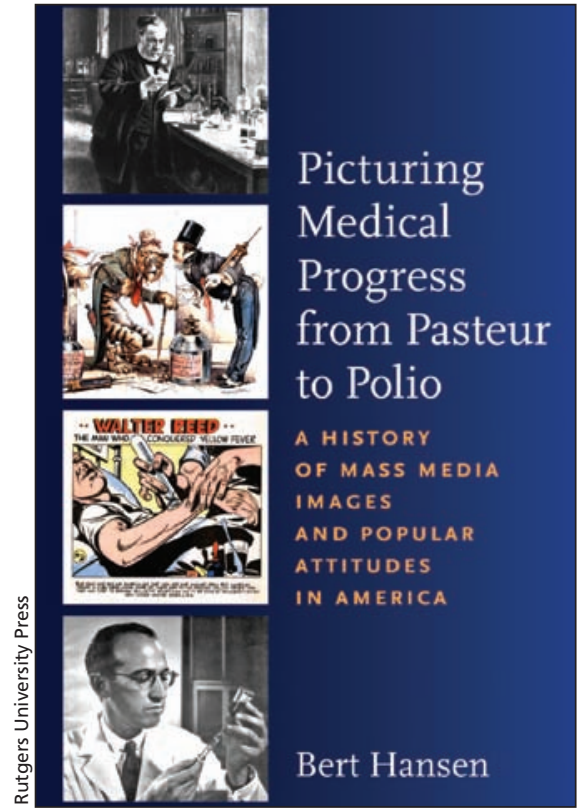

Picturing Medical Progress from Pasteur to Polio: A History of Mass Media Images and Popular Attitudes in America Bert Hansen

Rutgers University Press; 2009.

I $\mathrm{n}$ a recent essay in these pages, Anne Ishii introduced readers to the Japanese "renegade doctor," Black Jack. 'This superhero surgeon, who features in 17 works of "medical manga" (a type of adult comic book), may well be a 21 st century replacement for the very real, but no less heroic, individuals highlighted in Bert Hansen's new book.

With pictures and words, Hansen's work of history assesses the stories about medicine and science that were woven extensively, if not always accurately, into popular American culture in the decades between the 1880s and 1950. These stories and illustrations reached mass audiences through their reproduction - and repetition - in widely read mainstream magazines, newspapers, comics, films and on the radio.

It isn't easy to grasp how pervasive the popular images and storylines about
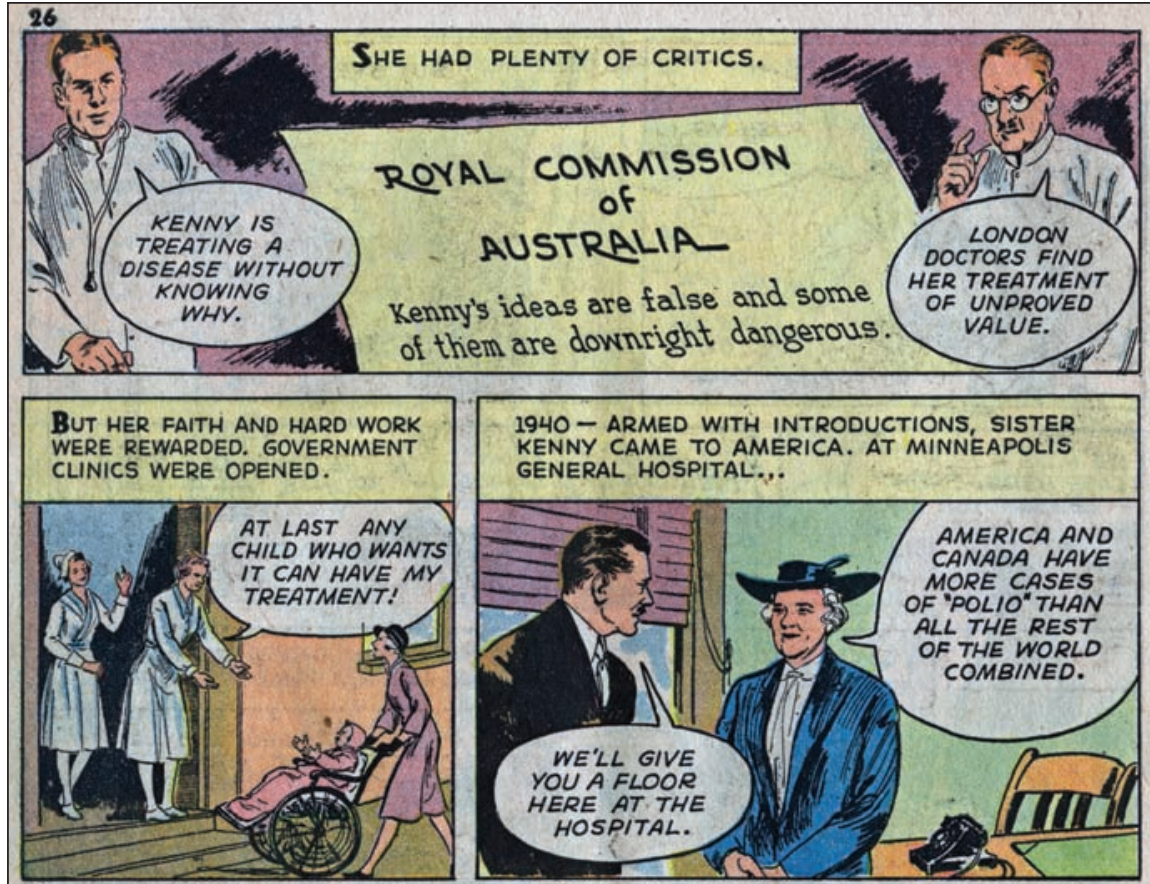
1940 - ARMED WITH INTRODUCTIONS, SISTER KENNY CAME TO AMERICA. AT MINNEAPOLIS GENERAL HOSPITAL.,.
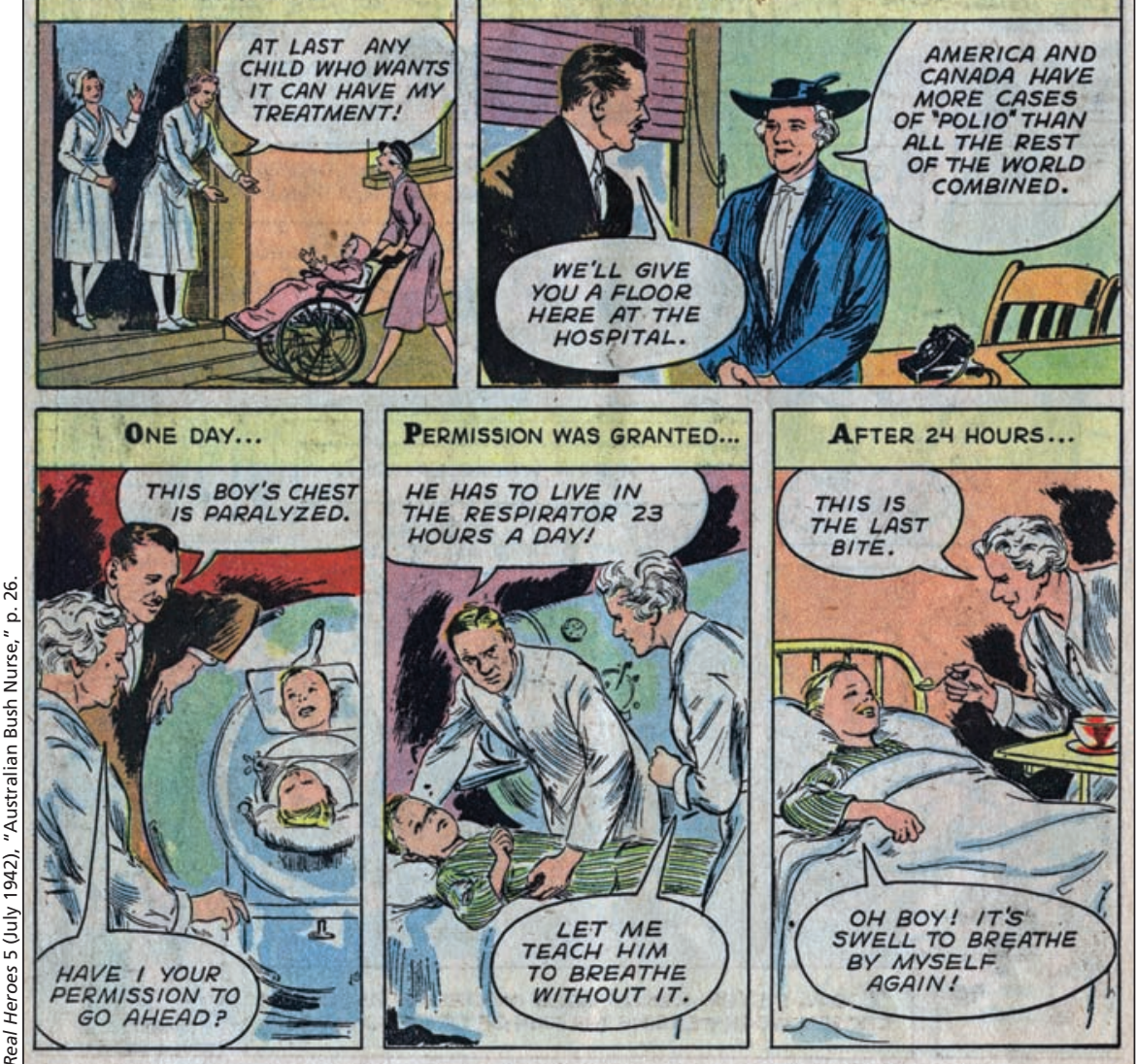

These three frames of a six-page story tell how Sister Elizabeth Kenny's innovative therapy for polio patients was at first rejected by the medical establishment in Australia and abroad. It was eventually given trials there and in North America because of her heroic persistence (Picturing Medical Progress, p. 196).

medical research and researchers were then. For the first time, millions of people were introduced to the same people and events in easily accessible ways in fiction and nonfiction formats and feature-length films. Moreover, these widely shared and repeated images generally had the same "plot" line: medical research had regular successes and made steady progress, and researchers and practitioners were invariably heroic. What a far cry from today when con- 


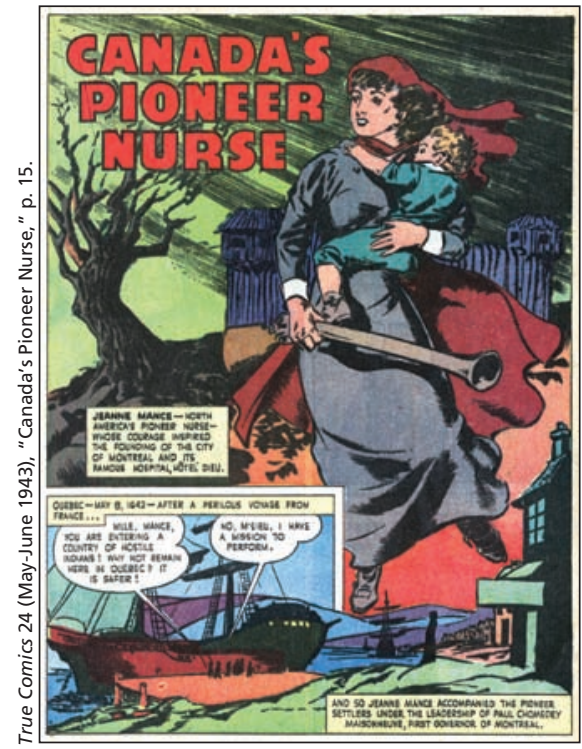

The opening frame of a four-page story about Jeanne Mance shows her holding a musket to protect a child from the dangers of a frontier settlement and proclaims that "her courage inspired the founding of the city of Montréal and its famous hospital, Hôtel Dieu." The American comic books of this era also included other Canadian medical heroes, such as Wilfred Grenfell and Norman Bethune. And these books did not feature women solely as nurses; there were also stories about female doctors including Elizabeth Blackwell, Marie Zakrzewska, Mary Walker, Margaret Chung and Florence Rena Sabin (Picturing Medical Progress, p. 192).

flicts of interest and pharma-dominated research are more likely (and appropriately) to get headlines.

This book is a real joy. Hansen provides wonderful selections of the graphic material circulating among ordinary Americans in the late 19th and early 20th centuries to give contemporary readers a vivid sense of what comic books, trading cards, radio dramas and magazine illustrations were like then. His accompanying analyses make clear how the triumphs of both medicine and people (past and contemporary) were regularly highlighted in ways that made them recognizable to potentially everyone: think of and see in this book - Jeanne Mance (romantically portrayed as "Canada's Pioneer Nurse," with baby in one arm, musket in the other), Joseph Goldberger (starring as "famine fighter"), and Walter Reed (the featured "conqueror" of yellow fever), for example, as heroes in the pages of comic books that were bought,

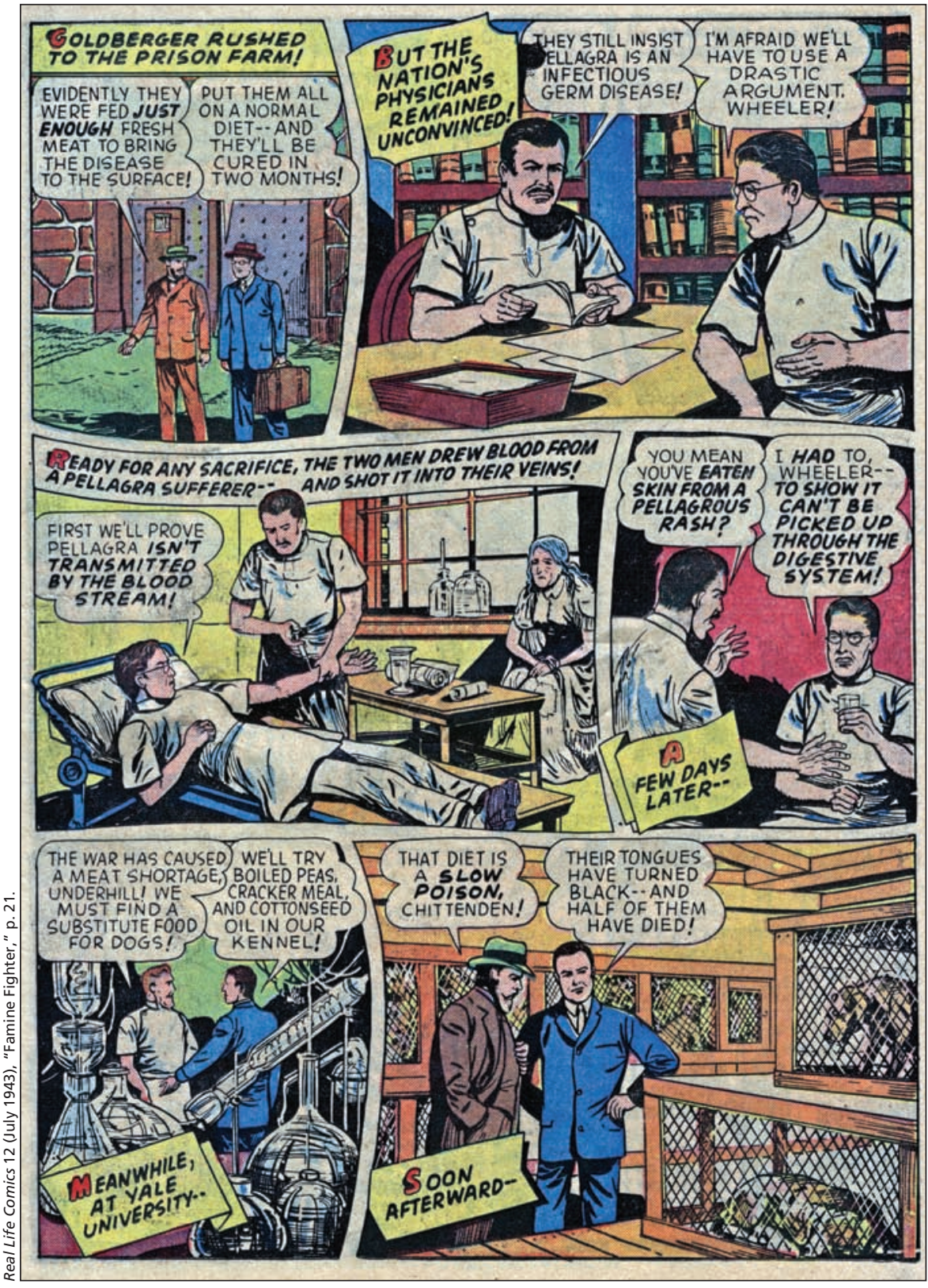

In this page from a story about Dr. Joseph Goldberger, who discovered the dietary deficiency that caused pellagra (niacin deficiency), we see how he and his colleagues, who lacked an animal model for the disease, held "filth parties" in which they ingested scabs and received blood injections from patients with pellagra to demonstrate that the ailment was not an infectious disease. As in many of the comic books' medical stories of the 1940s, children were led to see the value of careful experiments, including those using human and animal subjects (Picturing Medical Progress, color plate 16).

read, collected and traded by adults as well as children!

The extensive reproductions (colour and black-and-white), along with Hansen's very readable prose, help us understand how the imagery of medical progress nurtured a climate for public support of medical research: notions of "quest" and "discovery" were reinforced and sustained, with the media about and public attitudes toward science co-creating each other.

Although this book rightfully stands on its own as history, it is nevertheless tempting to consider it in light of contemporary mass media about science and medicine. Readers will likely have their own associations, but what comes immediately to mind are contemporary iconic uses of the DNA double helix as 
well as all the front-page stories of some "major" medical finding - too often, perhaps, framed as a discovery of the "gene for" whatever will be the disease-of-the-week. Clearly, a strong strain of what Hansen calls "triumphalism" has persisted over the years.

Hansen ends his book in the 1950s, when the arc of progress lavishly illustrated for many previous decades as failure-free could no longer be sustained. Stories about medical disasters became widely known (e.g., thalidomide) and the consistent success "plot" had to be rewritten. No less in need of revision were images of physicians as only selfless heroes.

If Hansen were to write a sequel covering the last 50 years, the splintering of the media, as well as the multiple and conflicting stories and illustrations we have about medical research and researchers today, would likely preclude a similar summary - even if only the American stories were told. Nevertheless, because I read this book shortly after the second wave of the H1N1 pandemic, I'd at least like to hope that historians and popular culture experts have been gathering the iconography that was used in symbiotic ways to picture the experience and shape attitudes to the pandemic: We will need the lessons this history has to offer.

\section{Abby Lippman PhD}

Professor

Department of Epidemiology, Biostatistics and Occupational Health

McGill University

Montréal, Que.

\section{Reference}

1. Ishii A. Medical manga comes to America. CMAJ 2009; 180:542-3.

CMAJ 2012. DOI:10.1503/cmaj.110261

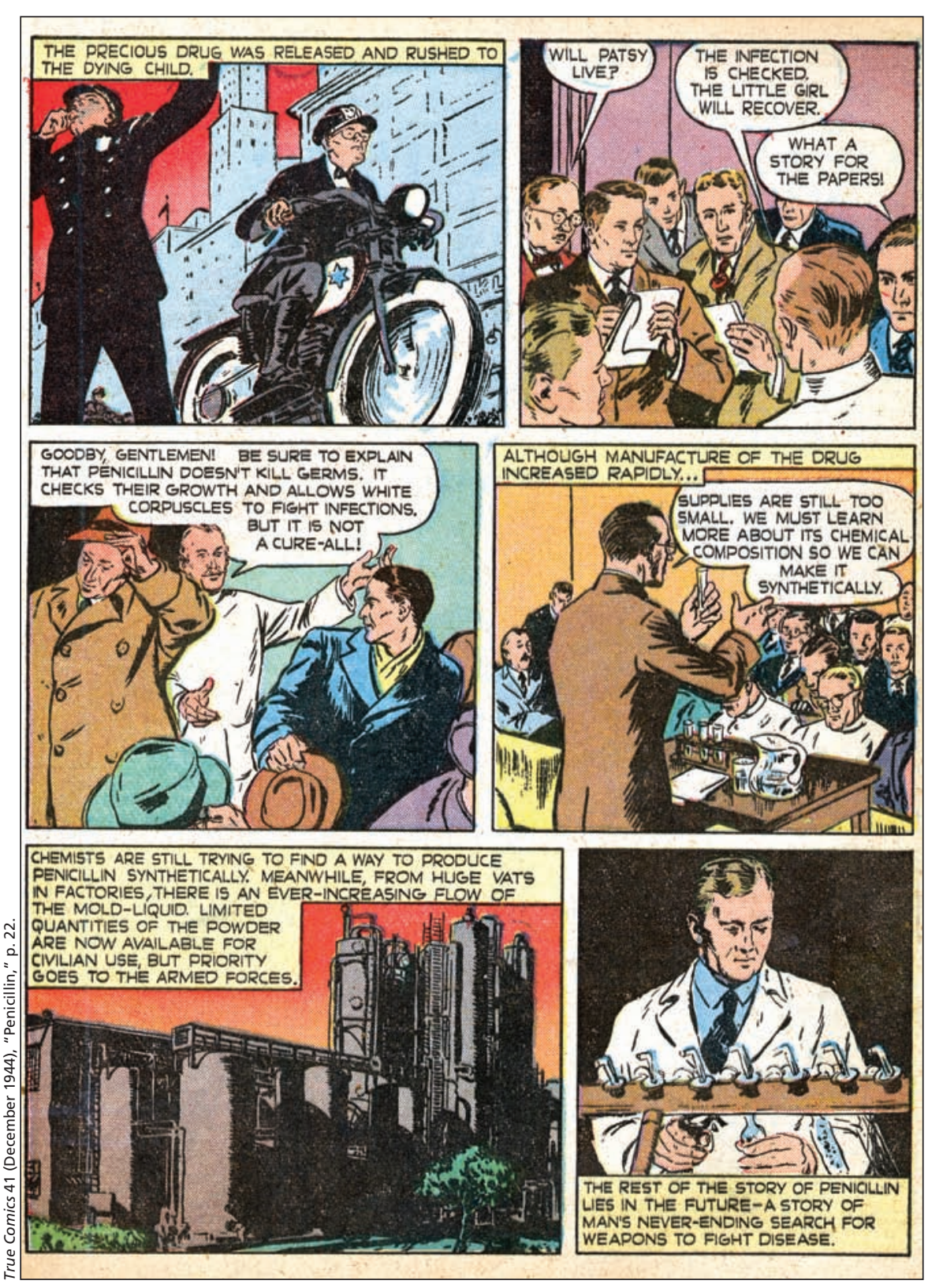

This story narrated the development of the first wonder drug by Sir Alexander Fleming and its earliest applications, including the media attention surrounding the first patients to receive penicillin. The story of little Patsy Malone, who survived, was a natural subject for a children's comic book, but it also appeared in many newspapers and her photograph made it into Time magazine (Picturing Medical Progress, p. 175). 